\title{
Genetic polymorphism of the glutathione S-transferase M1 and T1 genes in three distinct Arab populations
}

\author{
Abdel Halim Salem ${ }^{\mathrm{a}, \mathrm{b}, *}$, Alaeddin Yaqoob ${ }^{\mathrm{c}}$, Muhalab Ali $^{\mathrm{d}}$, Shailandra Handu ${ }^{\mathrm{e}}$, Raouf Fadel ${ }^{\mathrm{a}, \mathrm{b}}$, \\ Marwan Abu-Hijleh ${ }^{\mathrm{a}}$ and Wassim Almawi ${ }^{\mathrm{d}}$ \\ ${ }^{a}$ Department of Anatomy, College of Medicine and Medical Sciences, Arabian Gulf University, Manama, Bahrain \\ ${ }^{\mathrm{b}}$ Department of Anatomy, Faculty of Medicine, Suez Canal University, Ismailia, Egypt \\ ${ }^{\mathrm{c}}$ Salmaniya Medical Complex, Ministry of Health, Manama, Bahrain \\ ${ }^{\mathrm{d}}$ Department of Biochemistry, College of Medicine and Medical Sciences, Arabian Gulf University, Manama, \\ Bahrain \\ ${ }^{\mathrm{e}}$ Department of Pharmacology and Therapeutics, College of Medicine and Medical Sciences, Arabian Gulf \\ University, Manama, Bahrain
}

\begin{abstract}
Deletion polymorphisms for the glutathione S-transferase (GST) gene are associated with increased risk of cancer, and are implicated in detoxifying mutagenic electrophilic compounds. GST Polymorphic variants were reported for different populations. The aim of this study was to investigate the frequencies of GSTM1 and GSTT1 null genotypes among Bahraini, Lebanese and Tunisian Arabs. GST genotyping was done by multiplex PCR-based methods. Study subjects comprised 167 Bahrainis, 141 Lebanese and 186 Tunisians unrelated healthy individuals. GSTM1 deletion homozygosity of 49.7\%, 52.5\% and $63.4 \%$ were recorded for Bahraini, Lebanese and Tunisians, respectively. Among Bahrainis, the prevalence of GSTT1 null homozygotes was $28.7 \%$, while in higher rates were seen in Lebanese (37.6\%) and Tunisians (37.1\%). Our results indicate that there are no major differences in allelic distribution of GSTM1 and GSTT1 genes between the three Arab populations investigated except between Bahrainis and Tunisians regarding the allelic distribution of GSTM1 gene $(P=0.013)$. Combined analysis of both genes revealed that $14.4 \%$ of Bahrainis, $16.3 \%$ of Lebanese and $21.0 \%$ of Tunisians harbor the deleted genotype of both genes. This is the first study that addresses GST gene polymorphism in Bahraini and Lebanese Arabs, and will help genetic studies on the association of GSTM1 and GSTT1 polymorphisms with disease risks and drug effects in Arab populations.
\end{abstract}

Keywords: Glutathione S-transferase, genetic polymorphisms, Arabs

\section{Introduction}

Drugs differentially affect patients with the same disease, despite the similarity in dosing regimen, and individual variations in response to cancer therapy, and to toxic chemicals are attributed to the genetic differences in the drug metabolizing enzymes. As such, polymorphisms in genes encoding transporters, receptors,

*Address for correspondence: Dr. Abdel Halim Salem, Department of Anatomy, College of Medicine and Medical Sciences, Arabian Gulf University, 22979 Manama, Kingdom of Bahrain. Tel.: +973 17239650; Fax: +973 17271090; E-mail: ahaleemfd@agu.edu.bh.
DNA repair enzymes, drug targets and genes involved in the metabolism of xenobiotics are the main causes of patient's heterogeneity [1]. Assessment of polymorphisms of these genes in different populations may explain, at least in part, the variation in response to cancer therapy and to toxic chemicals. Most gene products are involved either in metabolic oxidation (phase I), or in detoxification (phase II) of toxic materials.

Glutathione S-transferases (GSTs) are a class of phase II enzymes present in many tissues, and are involved in xenobiotic detoxification, and thus contribute to the protection from broad range of compounds including carcinogens, chemotherapeutic agents, and en- 
vironmental pollutants [1,2]. Five classes of GST enzymes were described in humans: Alpha $(\alpha), \mathrm{Mu}(\mu)$, $\operatorname{Pi}(\pi)$, Zeta $(\zeta)$ and Theta $(\theta)$, with one or more genes in each class. Two major polymorphisms of the GSTM1 gene (chromosome 1p13.3) and GSTT1 gene (chromosome $22 \mathrm{q} 11.23$ ), result from gene deletion, and are associated with absent enzymatic activity in individuals carrying both deletions (i.e. null genotype) $[3,4]$. Functionally, the GSTM1 and GSTT1 null genotype is associated with differential susceptibility to various forms of cancer [5], resistance to chemotherapy treatment, drug response [6], and disease susceptibility and outcome $[7,8]$.

Varied distribution of GSTM1 and GSTT1 null genotypes was reported in different populations [1]. Approximately half of the Caucasian populations are homozygous deleted for GSTM1 null allele, and hence fail to express the enzyme [1]. The frequencies of homozygous deletions of GSTM1 gene are higher in Caucasians and Asians than in Africans [9], whereas homozygous deletions of GSTT1 gene are higher in Asians and Africans than in Caucasians [5]. Comprehensive reports of variations in the frequency of polymorphisms of GSTM1 and GSTT1 genes profiled Caucasians, Asians and Africans but not Arabs [10]. Given that gene polymorphism may predispose these populations to certain adverse drug reactions or disease occurrence, here we analyzed the frequency of GSTM1 and GSTT1 polymorphisms in three distinct Arab populations.

\section{Subjects and methods}

\subsection{Subjects}

Blood was collected in EDTA-containing tubes from 167 unrelated healthy Bahrainis from the Arabian Gulf University, Manama, from 141 unrelated healthy Lebanese from the city of Beirut, and from 186 Tunisians from Sousse (Central Tunisia). A written informed consent was obtained from all participants, and the study was done under institutionally-approved internal review board (IRB) protocols.

\subsection{GSTM1 and GSTT1 Genotype analysis}

Genomic DNA was isolated from blood samples by phenol-chloroform extraction followed by ethanol precipitation. GSTMI and GSTT1 genotyping were determined by multiplex PCR, using CYPIAl gene as con- trol, as previously described [11]. DNA was amplified in a total volume of $25 \mu \mathrm{l}$ with GSTM1 forward (5' GAA CTC CCT GAA AAG CTA AAG C 3') and reverse (5' GTT GGG CTC AAA TAT ACG GTG G 3') primers, and GSTT1 forward (5' TTC CTT ACT GGT CCT CAC ATC TC 3') and GSTT1 reverse (5', TCA CCG GAT CAT GGC CAG CA 3') primers. As internal control, exon 7 of $C Y P 1 A 1$ gene was amplified, using the following forward (5' GAA CTG CCA CTT CAG CTG TCT 3') and reverse (5' CAG CTG CAT TTG GAA GTG CTC 3') primers [11]. PCR consisted of an initial denaturation $\left(94^{\circ} \mathrm{C}\right.$ for $\left.5 \mathrm{~min}\right)$ followed by 32 cycles of denaturation $\left(94^{\circ} \mathrm{C}\right.$ for $\left.1 \mathrm{~min}\right)$, annealing $\left(59^{\circ} \mathrm{C}\right.$ for $\left.1 \mathrm{~min}\right)$, and extension $\left(72^{\circ} \mathrm{C}\right.$ for $\left.1 \mathrm{~min}\right)$. PCR product from co-amplification of GSTM1 (215 bp) and GSTT1 (480 bp) were run on $1.5 \%$ agarose gel; DNA bands were visualized under UV transillumination. Presence of the particular allele was designated as wild genotype (positive) and homozygous absence or deletion of the allele was designated as null genotype.

\subsection{Statistical analysis}

Data were expressed as number of alleles/genotypes, and percent of total. Allele frequencies were calculated by direct counting, and were evaluated using the chi square goodness-of-fit test.

\section{Results}

GSTM1 and GSTT1 genotyping were assessed by multiplex PCR in 167 Bahraini, 141 Lebanese and 186 Tunisian subjects. While this method does not differentiate between wild-type and heterozygous states, it determines the percentages of the homozygous deletion of both GSTM1 and GSTT1 genes. GST genotypes were coded as positive (wild-type homozygotes and deletion heterozygotes), or as null (homozygous deletion). This made direct calculation of Hardy Weinberg Equilibrium impossible.

In the present study, the frequencies of GSTM1 null genotype were $49.7 \%$ in Bahraini, $52.5 \%$ in Lebanese and $63.4 \%$ in Tunisians. The frequencies of GSTT1 null genotype were $28.7 \%$ in Bahrainis, $37.6 \%$ in Lebanese and $37.1 \%$ in Tunisians. GSTM1 and GSTT1 null genotype frequencies and the combined GSTM1 null + GSTT1 null genotype frequencies (double null genotype) was $14.4 \%$ in Bahraini, $16.3 \%$ in Lebanese, and $21.0 \%$ in Tunisians (Table 1).

Table 2 shows null-genotype frequencies for the GSTM1 and GSTT1 in various populations of Arabs, Asians, Africans, and Europeans using the Chi square test for goodness of fit. 
Table 1

Frequency of GSTs null genotypes in three Arab population

\begin{tabular}{lccccccc}
\hline \multicolumn{6}{c}{ Genotype frequency (\%) } \\
\hline Population & $\mathrm{n}$ & \multicolumn{2}{c}{ GSTM1 } & & \multicolumn{2}{c}{ GSTT1 } & \multirow{2}{*}{ double null } \\
\cline { 3 - 4 } \cline { 6 - 8 } & & positive & null & & positive & null & \\
\hline Bahrainis & 167 & $84(50.3 \%)$ & $83(49.7 \%)$ & & $119(71.3 \%)$ & $48(28.7 \%)$ & $24(14.4 \%)$ \\
Lebanese & 141 & $67(47.5 \%)$ & $74(52.5 \%)$ & & $88(62.4 \%)$ & $53(37.6 \%)$ & $23(16.3 \%)$ \\
Tunisians & 186 & $68(36.6 \%)$ & $118(63.4 \%)$ & & $117(62.9 \%)$ & $69(37.1 \%)$ & $39(21 \%)$ \\
\hline
\end{tabular}

$n=$ number of tested individuals.

Table 2

Frequency of GSTs null genotypes in various ethnic groups

\begin{tabular}{|c|c|c|c|c|c|}
\hline Population & $\mathrm{n}$ & \% GSTM1 null & \% GSTT1 null & $\%$ double null & Reference \\
\hline \multicolumn{6}{|l|}{ Arabs } \\
\hline Bahrainis & 167 & 49.7 & 28.7 & 14.4 & Present study \\
\hline Lebanese & 141 & 52.5 & 37.6 & 16.3 & Present study \\
\hline Tunisians & 186 & 63.4 & 37.1 & 21 & Present study \\
\hline Egyptians & 200 & 55.5 & 29.5 & NA & [17] \\
\hline Saudi & 513 & 54.6 & 25 & 17.2 & [15] \\
\hline \multicolumn{6}{|l|}{ Asians } \\
\hline Turkish & 133 & 51.9 & 17.3 & NA & [24] \\
\hline Iranians & 229 & 44.7 & 21.2 & NA & [25] \\
\hline Indians & 198 & 20.7 & 18.2 & NA & [29] \\
\hline Chinese & 735 & 56.5 & 56.5 & 31.4 & [26] \\
\hline Japanese & 143 & 44.1 & 43.4 & 15.4 & [28] \\
\hline Koreans & 1051 & 53.8 & 54.3 & 29.1 & [27] \\
\hline \multicolumn{6}{|l|}{ Europeans } \\
\hline British & 373 & 54 & 18 & NA & [20] \\
\hline French & 1184 & 53.4 & 16.8 & NA & [10] \\
\hline German & 734 & 51.6 & 19.5 & NA & [10] \\
\hline Austrian & 166 & 49 & 20 & NA & [23] \\
\hline \multicolumn{6}{|l|}{ Africans } \\
\hline Cameroonians & 126 & 27.8 & 46.8 & NA & [32] \\
\hline Zimbabweans & 150 & 24 & 26 & NA & [30] \\
\hline Gambians & 337 & 20.2 & 37.1 & NA & [31] \\
\hline Ivory Coast & 133 & 36.1 & 33.1 & 14.3 & [33] \\
\hline
\end{tabular}

n, number of subjects. NA, data not available.

\section{Discussion}

Although the frequencies of GSTM1 and GSTT1 null genotypes have been reported in diverse ethnic groups [10,12], sparse data are available for Arab populations. Here we investigated the polymorphism at GST loci in Bahraini, Lebanese and Tunisian Arabs. While the distribution of GSTM1 and GSTT1 null genotypes were described previously for Tunisians [13,14], no data has been published for Bahraini and Lebanese. We found that homozygosity for the GSTM1 deletion was generally comparable between Bahraini (49.7\%) and Lebanese $(52.5 \%)$ samples tested. Despite the higher frequency of GSTMI null genotype in Tunisians (63.4\%) compared to Lebanese, no statistically significant differences were found. Statistically significant differences were detected only when we compared Bahrainis and Tunisians $(P=0.013)$, which may be due to ethnic mixture in these two populations. The ho- mozygosity for the GSTMI deletion in the three Arab populations were comparable to those reported for Saudi Arabian (54.6\%) [15,16] and Egyptian (55.5\%) [17] Arabs (Table 2).

GSTM1 null genotype are not uniformly distributed among diverse population, but an ethnic and geographic basis of distribution was suggested [10,18]. The prevalence of individuals not expressing the GSTM1 enzyme due to a homozygous gene deletion is reportedly higher in Europeans and Asians, as compared to Africans [1]. The GSTM1 null genotype frequencies vary from $38-67 \%$ in Europeans, $33-63 \%$ in Asians, and $16-36 \%$ in sub-Saharan Africans $[10,19]$. The prevalence of GSTM1 homozygous deficiency seen here was comparable for Europeans, including British (54\%) [10,20], French (51\%) [21], German (52\%) [22] and Austrians (49\%) [23]. In addition, they were comparable to Asians, such as Turkish (51.9\%) [24], Iranians $(44.7 \%)$ [25], Chinese $(56.5 \%)$ [26], Koreans 


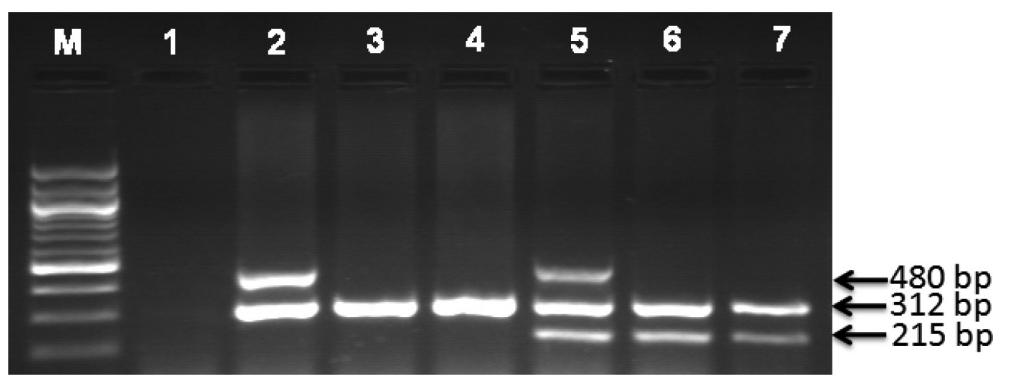

Fig. 1. Multiplex PCR products analyzed on 1.5\% agarose gel. The presence or absence of GSTT1 and GSTM1 genes was detected by the presence of a band at $480 \mathrm{bp}$ (corresponding to GSTT1) and a band at $215 \mathrm{bp}$ (corresponding to GSTM1). A band at 312 bp (Corresponding to CYP1Al gene) was always present and was used as an internal control to document successful PCR amplification. Lane 1, a negative control. Lane 2, an individual with GSTT1 present (480 bp) and GSTM1 null alleles. Lanes 3 and 4: individuals with null alleles for both GSTT1 and GSTM1 genes showing only one band at 312 bp corresponding to the internal control (CYP1Al gene fragment). Lane 5, an individual with both GSTT1 and GSTM1 alleles present. Lanes 6 and 7: individuals harboring GSTT1 null and GSTM1 present (215 bp) alleles. M is a DNA molecular marker.

$(53 \%)$ [27] and Japanese (44\%) [28] (Table 2). Significant differences in GSTM1 null genotype distribution were seen with respect to Indians $(20.7 \%)$ [29], and Africans, including Zimbabweans (24\%) [30], Gambians (20.2\%) [31], Cameroonians (27.8\%) [32], and Ivory Coast (36.1\%) [33] (Table 2).

The prevalence of GSTT1 null homozygotes was $28.7 \%$ in Bahraini, which was lower (though not statistically significant) than the rates seen for (Lebanese $37.6 \%$ ) and Tunisians (37.1\%). In our hands, no differences were seen between the population studied and Saudi (25\%) [15,16] and Egyptian (29.5\%) [17] Arabs. Worldwide differences in GSTT1 frequencies were previously documented [10,12], with $20 \%$ of Caucasians, $60 \%$ of Asians and $40 \%$ of Africans not expressing the GSTT1 enzyme [5]. The frequencies of GSTT1 deletion in our populations were higher than that described for Europeans, including British (18\%) [20], French (16\%) [21], German (13\%) [22] and Austrian (20\%) [23], as well as for other Middle Eastern populations, including Turks (17.3\%) [24], and Iranians (21.2\%) [25], but was significantly lower than SouthEast Asians, such as Chinese (56.5\%) [26], Koreans $(53.8 \%)$ [27] and Japanese (44\%) [28]. The frequencies of GSTT1 null genotype in our Arab populations are similar to that of the sub-Saharan Africans: Zimbabweans (26\%) [30], Gambians (37.1\%) [31], Cameroonians $(46.8 \%)$ [32] and Ivory Coast $(33.1 \%)$ [33] (Table 2). The difference of GTSM1 and GSTT1 null alleles' frequency between our samples and those of others is attributed to their evolutionary histories, and also to selection arising from varied exposures to toxic substances.

Varied frequencies of GSTM1 and GSTT1 null genotypes were previously reported for Tunisians $(34.5 \%$,
$16.6 \%$, respectively) among 145 subjects [13] and ( $45.6 \%$ and $44.3 \%$, respectively) in 79 subjects [14]. In Tunisian samples, the frequency of GSTM1 null genotype $(63.4 \%)$ and comparable frequency of null genotype for GSTT1 (37.1\%), may be explained by the larger number of subjects examined in our study (186) compared with earlier studies. The distribution of GSTM1 null deletion in Tunisian $(63.4 \%)$ was higher, but that of the GSTT1 null genotype (37.1\%) was comparable to that of sub-Saharan Africans. This can be explained by the ethnic mixture of the Tunisians, with influence from both sub-Saharan Africans and Arabs. Our data showed that Bahrainis and Lebanese are similar to Europeans and Asians with regards to the frequency of GSTM1 null genotype, and to Asians and sub-Saharan Africans regarding the distribution of the GSTT1 null genotype.

The significance of the high frequencies of homozygous null deletions at these two loci remains to be seen. Relevant data on the prevalence of various diseases, particularly those related to exposure to toxic substances, in these populations are unavailable. Variable association between various GSTM1 and GSTT1 genotypes with senile cataract [34] and bladder cancer [35] among Egyptians, and with thyroid cancer [15] and glaucoma [36] in Saudi population was found. Therefore, it is difficult to ascertain either the causes of variation in the frequencies of these null deletions, or the implications of this variation on epidemiological profiles of diseases. The frequency reported for Tunisians $(21 \%)$ is the highest frequency described for Arab populations, with Asians having the highest frequencies of double null genotype (20-33\%), with Africans and Europeans prevalence rates ranging from $10.4-17.2 \%$ [1]. The frequency of the double null genotypes in our popula- 
tions was similar to that found in Saudi $(17.2 \%)[15$, $16]$, and to Africans from Ivory Coast (14.3\%).

Cancer is an increasing problem in the Arabic countries and it ranks as the fourth leading cause of death among the Arabs [37]. The age standardized incidence (ASR) of all cancers among the Arabs is currently 3 to 4 times lower than in the industrialized countries but is expected to double in the next 15 years [37]. ASR of all cancers per 100.000 in Bahrain is 118 in males and 108 in females [38], in Lebanon is 169 in males and 176 in females [39] and in Tunisia is 114 in males and 78 in females [40]. Associations of GSTM1 and/or GSTT1 null genotypes with several types of cancer have been reported and represent an area of intensive research [5,9, $15,19,23,26]$. The identification of high frequencies of GSTM1 and GSTT1 null alleles in Arabs has its clinical importance as GSTs genes modulate response to cancer treatment associated toxicity. On the other hand, the risk of cancer is modulated by the ethnic background and environmental factors. So, case/control studies that test the potential risk of the GST null alleles in Arabs will contribute in the definition of gene-gene and gene-environment interactions.

In conclusion, this is the first report on the polymorphic distribution of the GSTM1 and GSTT1 genotypes in three Arab populations. In this study, we provide a reference database of allelic distribution of the GSTM1 and GSTT1 genotypes in these populations. This data will serves as a template for future clinical research associated with cancer and drugs pharmacogenomics in the Arab populations. Further detailed studies of GST variants and other metabolic gene polymorphisms associated with response to chemotherapeutic drugs and susceptibility to cancer could be helpful in understanding their roles as genetic susceptibility markers in Arabs.

\section{Acknowledgment}

This work was supported by a grant from the Arabian Gulf University, Grant number 60/2010.

\section{References}

[1] G. Ginsberg, S. Smolenski, D. Hattis, et al., Genetic Polymorphism in Glutathione Transferases (GST): Population distribution of GSTM1, T1, and P1 conjugating activity, J Toxicol Environ Health B Crit Rev 12 (2009), 389-439.

[2] H.M. Bolt and R. Thier, Relevance of the deletion polymorphisms of the glutathione S-transferases GSTT1 and GSTM1 in pharmacology and toxicology, Curr Drug Metab 7 (2006), $613-628$.
[3] S. Xu, Y. Wang, B. Roe and W.R. Pearson, Characterization of the human class Mu glutathione S-transferase gene cluster and the GSTM1 deletion, J Biol Chem 273 (1998), 3517-3527.

[4] S. Pemble, K.R. Schroeder, S.R. Spencer et al., Human glutathione S-transferase theta (GSTT1): cDNA cloning and the characterization of a genetic polymorphism, Biochem J 300 (1994), 271-276.

[5] R.C. Strange and A.A. Fryer, The glutathione S-transferases: influence of polymorphism on cancer susceptibility, IARC Sci Publ 148 (1999), 231-249.

[6] J.D. Hayes and D.J. Pulford, The glutathione S-transferase supergene family: regulation of GST and the contribution of the isoenzymes to cancer chemoprotection and drug resistance, Crit Rev Biochem Mol Biol 30 (1995), 445-600.

[7] J. Lear, A. Heagerty, A. Smith et al., Polymorphism in detoxifying enzymes and susceptibility to skin cancer, Photochem Photobiol 63 (1996), 424-428.

[8] A.A. Fryer, A. Bianco, M. Hepple et al., Polymorphism at the glutathione S-transferase GSTP1 locus. A new marker for bronchial hyperresponsiveness and asthma, Am J Respir Crit Care Med 161 (2000), 1437-1442.

[9] L.R. Bailey, N. Roodi, C.S. Verrier et al., Breast cancer and CYPIA1, GSTM1, and GSTT1 polymorphisms: evidence of a lack of association in Caucasians and African Americans, Cancer Res 58 (1998), 65-70.

[10] S. Garte, L. Gaspari, A.K. Alexandrie et al., Metabolic gene polymorphism frequencies in control populations, Cancer Epidemiol Biomarkers Prev 10 (2001), 1239-1248.

[11] S.Z. Abdel-Rahman, R.A. el-Zein, W.A. Anwar and W.W. $\mathrm{Au}, \mathrm{A}$ multiplex PCR procedure for polymorphic analysis of GSTM1 and GSTT1 genes in population studies, Cancer Lett 107 (1996), 229-233.

[12] H.H. Nelson, J.K. Wiencke, D.C. Christiani et al., Ethnic differences in the prevalence of the homozygous deleted genotype of glutathione S-transferase theta, Carcinogenesis 16 (1995), 1243-1245.

[13] S. Gara, M. Abessi, K. Bendjemena et al., Deletion polymorphism of glutathione s-transferases $\mathrm{m} 1$ and $\mathrm{t} 1$ in the tunisian population, Tunis Med $\mathbf{8 8}$ (2010), 700-702.

[14] S. Ouerhani, F. Tebourski, M.R. Slama et al., The role of glutathione transferases M1 and T1 in individual susceptibility to bladder cancer in a Tunisian population, Ann Hum Biol 33 (2006), 529-535.

[15] A.K. Siraj, M. Ibrahim, M. Al-Rasheed, et al., Polymorphisms of selected xenobiotic genes contribute to the development of papillary thyroid cancer susceptibility in Middle Eastern population, BMC Med Genet 9 (2008), 61.

[16] R. Bu, M.I. Gutierrez, M. Al-Rasheed et al., Variable drug metabolism genes in Arab population, Pharmacogenomics $J$ 4 (2004), 260-266.

[17] S.I. Hamdy, M. Hiratsuka, K. Narahara et al., Genotype and allele frequencies of TPMT, NAT2, GST, SULT1A1 and MDR1 in the Egyptian population, Br J Clin Pharmacol 55 (2003), 560-569.

[18] A. Hatagima, C.F. Marques, H. Krieger and M.F. Feitosa, Glutathione S-transferase M1 (GSTM1) and T1 (GSTT1) polymorphisms in a Brazilian mixed population, Hum Biol $\mathbf{7 6}$ (2004), 937-942.

[19] T.R. Rebbeck, Molecular epidemiology of the human glutathione S-transferase genotypes GSTM1 and GSTT1 in cancer susceptibility, Cancer Epidemiol Biomarkers Prev 6 (1997), 733-743.

[20] H. Duncan, C. Swan, J. Green et al., Susceptibility to ulcerative colitis and Crohn's disease: interactions between glutathione 
S-transferase GSTM1 and GSTT1 genotypes, Clin Chim Acta 240 (1995), 53-61.

[21] N. Jourenkova, M. Reinikanen, C. Bouchardy et al., Effects of glutathione S-transferases GSTM1 and GSTT1 genotypes on lung cancer risk in smokers, Pharmacogenetics 7 (1997), $515-518$.

[22] V. Jahnke, C. Matthias, A. Fryer and R. Strange, Glutathione S-transferase and cytochrome-P-450 polymorphism as risk factors for squamous cell carcinoma of the larynx, Am J Surg 172 (1996), 671-673.

[23] A. Gsur, G. Haidinger, S. Hinteregger et al., Polymorphisms of glutathione-S-transferase genes (GSTP1, GSTM1 and GSTT1) and prostate-cancer risk, Int J Cancer 95 (2001), 152-155.

[24] A.O. Ada, S.H. Suzen and M. Iscan, Polymorphisms of cytochrome P450 1A1, glutathione S-transferases M1 and T1 in a Turkish population, Toxicol Lett 151 (2004), 311-315.

[25] A. Torkaman-Boutorabi, M. Hoormand, N. Naghdi et al., Genotype and allele frequencies of $\mathrm{N}$-acetyltransferase 2 and glutathione S-transferase in the Iranian population, Clin Exp Pharmacol Physiol 34 (2007), 1207-1211.

[26] K.A. Moy, J.M. Yuan, F.L. Chung et al., Isothiocyanates, glutathione S-transferase M1 and T1 polymorphisms and gastric cancer risk: a prospective study of men in Shanghai, China, Int J Cancer 125 (2009), 2652-2659.

[27] H.J. Cho, S.Y. Lee, C.S. Ki and J.W. Kim, GSTM1, GSTT1 and GSTP1 polymorphisms in the Korean population, J Korean Med Sci 20 (2005), 1089-1092.

[28] A. Morinobu, S. Kanagawa, M. Koshiba et al., Association of the glutathione S-transferase M1 homozygous null genotype with susceptibility to Sjogren's syndrome in Japanese individuals, Arthritis Rheum 42 (1999), 2612-2615.

[29] K.M. Girisha, A. Gilmour, S. Mastana et al., T1 and M1 polymorphism in glutathione S-transferase gene and coronary artery disease in North Indian population, Indian J Med Sci 58 (2004), 520-526.

[30] C. Dandara, J. Sayi, C.M. Masimirembwa et al., Genetic poly- morphism of cytochrome P450 1A1 (Cyp1A1) and glutathione transferases (M1, T1 and P1) among Africans, Clin Chem Lab Med 40 (2002), 952-957.

[31] C.P. Wild, F. Yin, P.C. Turner et al., Environmental and genetic determinants of aflatoxin-albumin adducts in the Gambia, Int J Cancer 86 (2000), 1-7.

[32] S. Piacentini, R. Polimanti, F. Porreca et al., GSTT1 and GSTM1 gene polymorphisms in European and African populations, Mol Biol Rep 38 (2011), 1225-1230.

[33] A. Santovito, C. Burgarello, P. Cervella and M. Delpero, Polymorphisms of cytochrome P450 1A1, glutathione stransferases M1 and T1 genes in Ouangolodougou (Northern Ivory Coast), Genetics and Molecular Biology 33 (2010), 434-437.

[34] A.A. Abdel Azeem, A.A. Mahmoud, M.M. Salaheldine and $\mathrm{K}$. Amr, Implication of glutathione S-transferase M1 and T1 polymorphisms in the development of senile cataract among Egyptians, Bratisl Lek Listy 110 (2009), 678-683.

[35] W.A. Anwar, S.Z. Abdel-Rahman, R.A. El-Zein et al., Genetic polymorphism of GSTM1, CYP2E1 and CYP2D6 in Egyptian bladder cancer patients, Carcinogenesis 17 (1996), 1923-1929.

[36] K.K. Abu-Amero, J. Morales, G.H. Mohamed et al., Glutathione S-transferase M1 and T1 polymorphisms in Arab glaucoma patients, Mol Vis 14 (2008), 425-430.

[37] Revised global burden of disease (GBD) 2002 estimates, Geneva, World Health Organization, (2002), http://www.who. int/healthinfo/bodgbd2002revised/en/index.html.

[38] Cancer incidence report of Gulf Cooperation Council States, Riyadh, Gulf Center for Cancer Registration, 2003.

[39] S.M. Adib and J. Daniel, Cancer in Lebanon, Beirut, Ministry of Health, National Cancer Registry, 2003.

[40] J. Ferlay, F. Bray, P. Pisani and D.M. Parkin, GLOBOCAN 2002: Cancer Incidence, Mortality and Prevalence Worldwide International Agency for Research on Cancer (IARC) CancerBase No. 5, version 2.0., Lyon: IARC Press, 2004. 


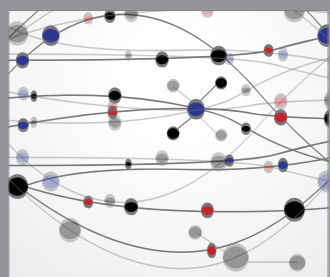

The Scientific World Journal
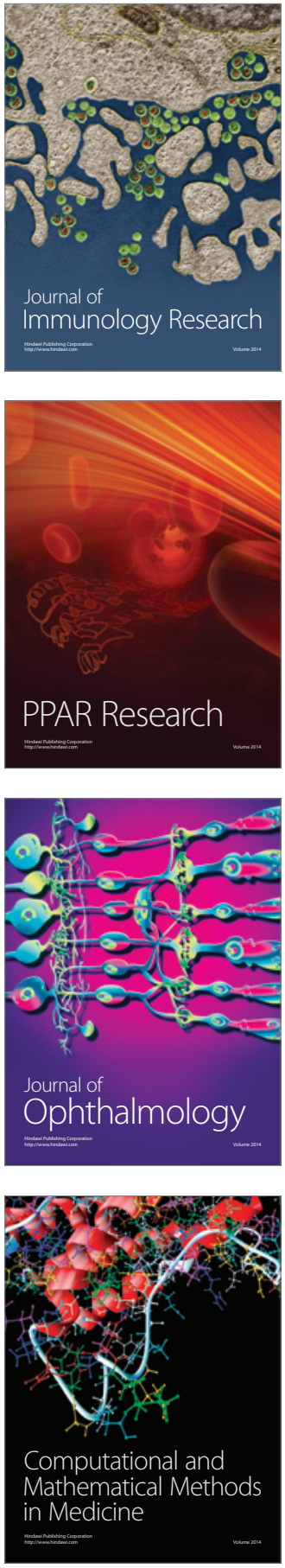

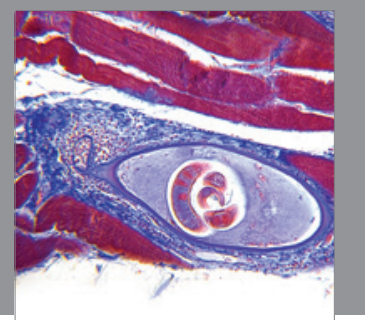

Gastroenterology

Research and Practice
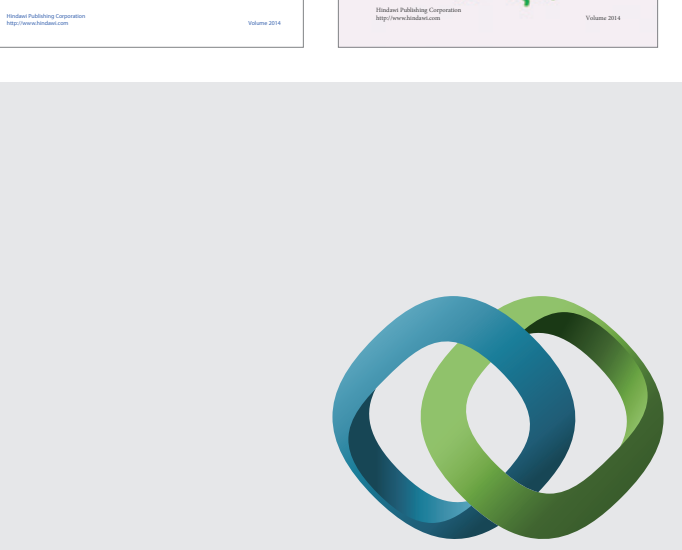

\section{Hindawi}

Submit your manuscripts at

http://www.hindawi.com
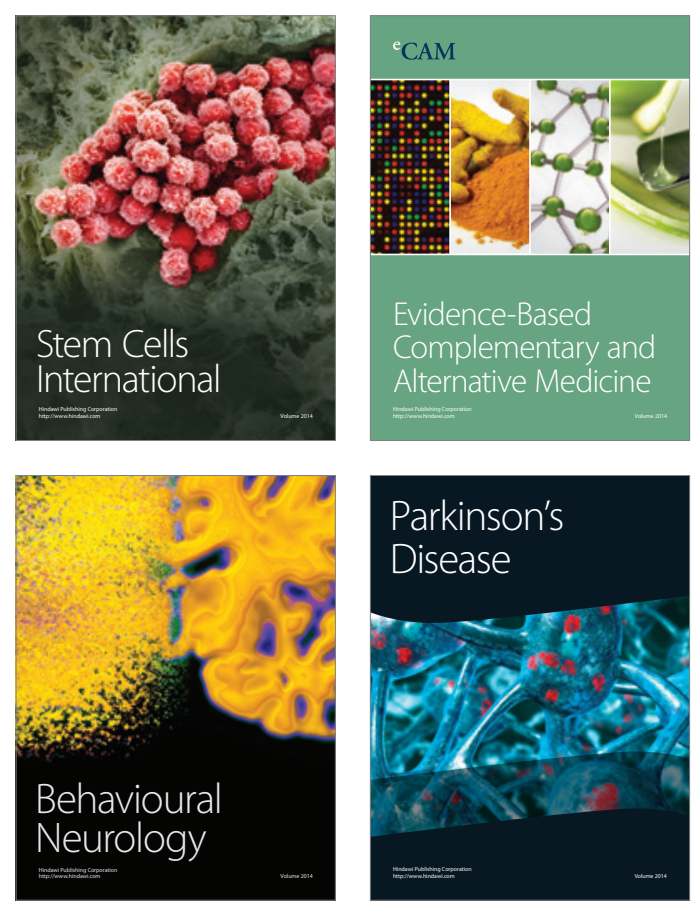

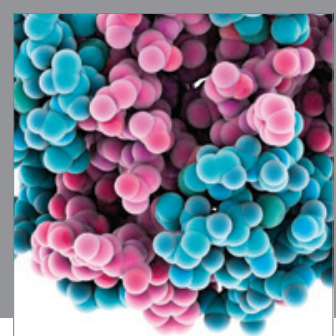

Journal of
Diabetes Research

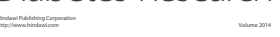

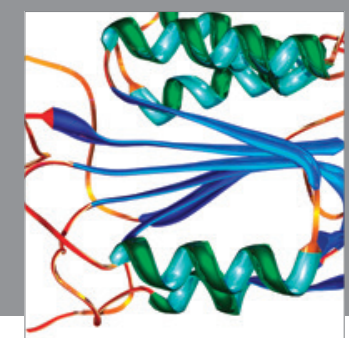

Disease Markers
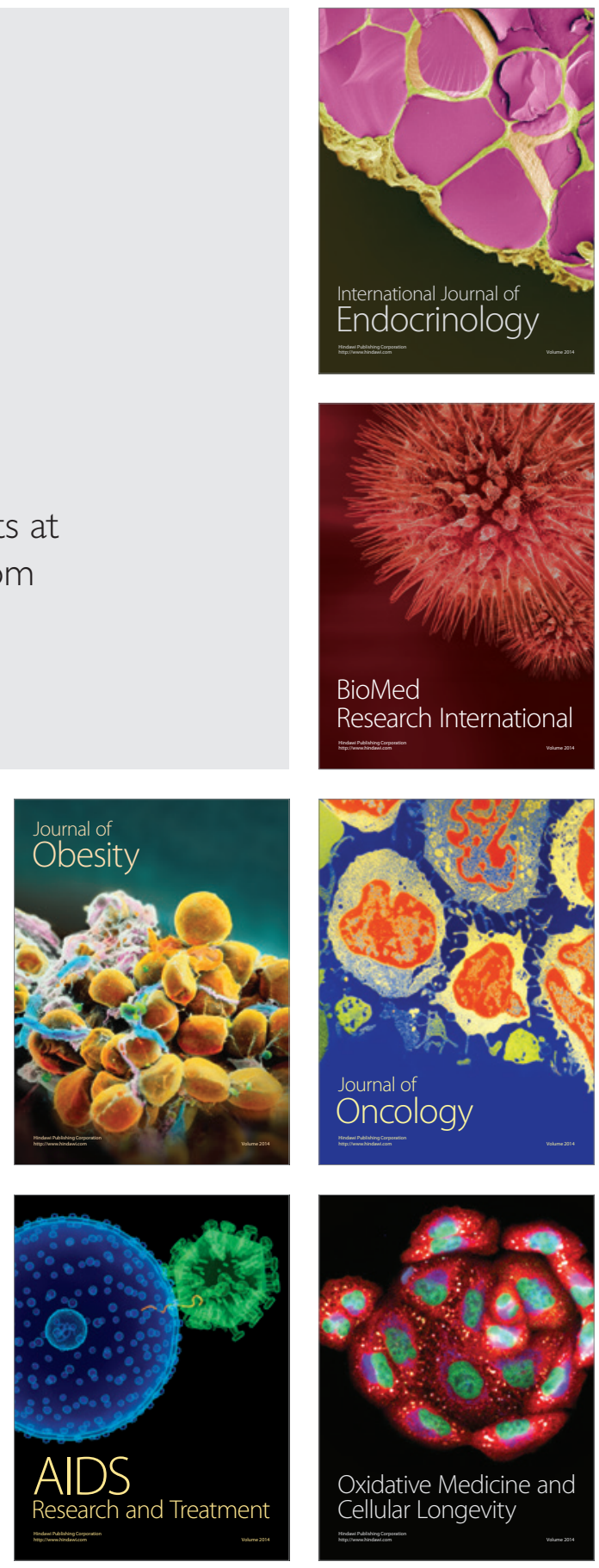